\title{
Intraoral versus Extraoral Measurement of the Height of the Interproximal Contact Area in Maxillary Anterior Teeth
}

\author{
Mohd G. Sghaireen ${ }^{a}$ Heyam Mobark Albhiran ${ }^{b}$ Ibrahim A. Alzoubi ${ }^{a}$ \\ Edward Lynch ${ }^{c}$ Mahmoud K. AL-Omirid, e

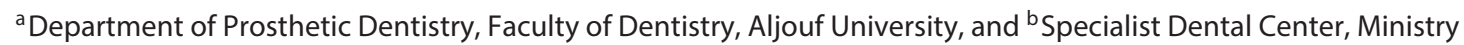 \\ of Health, Sakaka, Saudi Arabia; ' ${ }^{C}$ Dental Education and Research Center, Warwick Dentistry, Warwick Medical \\ School, Coventry, and ${ }^{\mathrm{d}}$ City of London School of Dentistry, London, UK; ${ }^{\mathrm{e}}$ Faculty of Dentistry, University of Jordan, \\ Amman, Jordan
}

\author{
Key Words \\ Contact point $\cdot$ Interproximal contact $\cdot$ Anterior teeth . \\ Dental esthetics
}

\begin{abstract}
Objectives: This study aimed to clinically quantify the apicoincisal height of the upper interproximal areas directly in patients' mouths compared to measurements on stone models. Subjects and Methods: One hundred and fifty participants ( 75 females and 75 males, age range $20-45$ years) were recruited for this study. A digital caliper was used to measure the anterior maxillary interproximal contact areas directly in patients' mouths and on stone models. The digital caliper accuracy was up to 0.01 . The Statistical Package for Social Sciences software (SPSS, version 19.0, Chicago, IIl., USA) was used for statistical analysis. Statistical significance was based on probability values $<0.05$. Results: The intraoral measurement of proximal contacts as well as the measurement on stone models showed that the dimensions of interproximal contacts on both sides of each tooth were significantly different $(p<0.001)$ and that the dimension of the mesial contact point was larger than that of the distal contact point of each tooth. The largest contact point was the one between
\end{abstract}

the central incisors (direct intraoral measurement $=2.9-6.49$ $\mathrm{mm}$; model measurement $=3.31-6.91 \mathrm{~mm}$ ). On the other hand, the contact point between the canine and first premolar was the smallest on both sides of the arch $(0.63-2.52 \mathrm{~mm}$ intraorally, $0.98-2.88 \mathrm{~mm}$ on models). The intraoral measurement of contact points was more accurate than model measurements, and the differences were statistically significant $(p<0.001)$. Conclusions: The clinical evaluation of contact point dimensions using a digital caliper was more precise than measuring contact points on stone models; hence, it is a viable, quick and adequate method to be used routinely.

(c) 2015 S. Karger AG, Basel

\section{Introduction}

Most smile esthetic components have received enormous attention by dental professionals and researchers. The interproximal contact area (ICA) is defined as the zone in which two adjacent teeth appear to meet [1]. The spaces that are formed coronally to the ICA are called 'spillway spaces' or 'embrasures'. They serve two main purposes: (1) to create a spillway for the escape of food

\section{KARGER 125}

E-Mail karger@karger.com www.karger.com/mpp

\section{(c) 2015 S. Karger AG, Basel} 1011-7571/15/0242-0136\$39.50/0

Karger

Open access

This is an Open Access article licensed under the terms of the Creative Commons Attribution-NonCommercial 3.0 Unported license (CC BY-NC) (www.karger.com/OA-license), applicable to the online version of the article only. Distribution permitted for non-commercial purposes only.
Prof. Mahmoud K. AL-Omiri

Department of Prosthodontics, Faculty of Dentistry, University of Jordan Amman 11942 (Jordan)

E-Mail alomirim@yahoo.co.uk 
during mastication, which reduces forces brought to bear upon the teeth, and (2) to prevent food from being forced through the contact area [2]. The spaces that are formed apically to the ICA are called 'interproximal spaces'; they are usually filled with the interdental papilla.

The design of the contact area, interproximal space and embrasures varies with the form and alignment of teeth, while both sections of the arch show a similarity of this design [2]. The gingival embrasure, the height of the interdental papilla and the incisal embrasure are all defined by the contact area [3,4]. The contact areas of the maxillary teeth are relevant for ensuring optimal 'pink esthetics' for patients with a high smile line (or visible cervical margins). The iconic study by Tarnow et al. [5], which produced the ' $\mathrm{mm}$ rule', stated that when the distance from the contact point to the interproximal osseous crest is $\leq 5 \mathrm{~mm}$, there would be a complete fill of the gingival embrasures with interdental papilla. The chance of a complete fill is progressively reduced by $50 \%$ for each millimeter increase above the 5-mm distance.

Therefore, during planning for anterior restoration, attention should be paid to the height of the ICA due to its importance in the final esthetic result. A low contact area might result in black triangles, while a high proximal contact area might impinge on the gum and cause unpleasant appearance [5].

The location of the ICA has been studied by Suilkowski [6] who stated that the ICA lies between the incisal and gingival embrasures. Stappert et al. [7] measured the proximal contact area on master cast from the apical point of the contact area, corresponding to the peak of the interdental papilla, to the incisal point of the contact area equivalent to the initiation of the incisal embrasure. $\mathrm{He}$ concluded that the proximal contact area decreased anteroposteriorly between maxillary central incisors to first premolars bilaterally, from 4 to 3 and 2 to $1.5 \mathrm{~mm}$, respectively. Tarnow et al. [5] and Martegani et al. [3] measured the distance between the bone crest and the facial aspect of the apical contact area by sounding the soft tissue. Martegani et al. [3] reevaluated the results by periapical radiographs. The most apical portion of the contact area was identified using a copper line fixed within the interdental embrasure.

Despite the fact that previous studies [3, 7-13] investigating smile esthetics addressed the importance of ICA in restoring anterior teeth, none of these studies have directly measured the height of the ICA clinically. Previous studies measured the proximal contact area by sounding the soft tissue [3,5], used master casts [7] or radiographs [3]. Therefore, the purpose of this study was to clinically

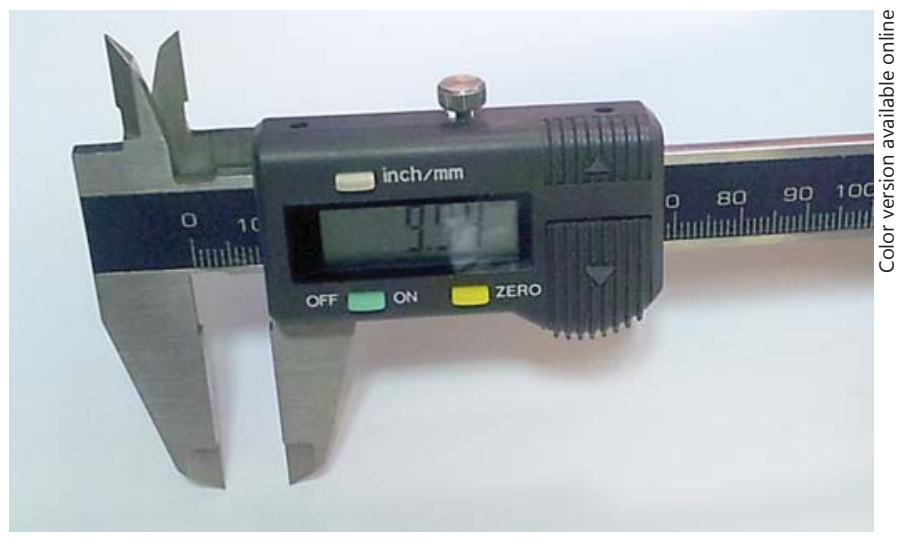

Fig. 1. The digital caliper (Terensa, USA) used for the measurement of the ICA between the upper anterior teeth.

quantify the apicoincisal height of the upper interproximal areas directly in patients' mouths and to compare the results to measurements obtained from stone models of the same teeth.

\section{Subjects and Methods}

One hundred and fifty participants ( 75 females and 75 males, age range $20-45$ years) were recruited for this study. The study was approved by the Deanship of Scientific Research, Aljouf University, Sakaka, Saudi Arabia. Patients' informed consent was obtained before being recruited for the study.

Inclusion criteria were good systemic health, well-aligned maxillary teeth, no incisal attrition, no fixed partial dentures or any other restorations and no missing teeth. The participants did not have previous orthodontic treatment. Exclusion criteria were participants with incisal attrition, fixed partial dentures, restorations or a history of orthodontic treatment, because these factors have the potential to affect proximal areas and thus affect the results. Before taking any measurements, each participant provided detailed dental and medical histories and received full oral examination by the investigator to ensure that the above inclusion criteria were satisfied.

The measurement of ICAs was carried out directly in patients' mouths using a digital caliper (Terensa, USA) (fig. 1) with a lightemitting diode display which has an accuracy of up to $0.01 \mathrm{~mm}$. The patients were requested to brush and floss their teeth before measurements. Each interproximal area was air dried before the measurement.

The beaks of the digital caliper as fabricated by the manufacturer were much tapered to a wedge shape with a pen-point tip which allows easy access of the beaks to the top and base of the proximal contact area. The measuring points on the proximal area were the visible touching areas of adjacent teeth both from the occlusal side and the gingival side. The beaks of the caliper were moved till they touched both the base and the top of the contact area between the adjacent teeth (gingivo-occlusal dimension of the 
Table 1. The means, SDs and minimum and maximum interproximal contact point distances among the measured teeth

\begin{tabular}{|c|c|c|c|c|c|c|c|c|}
\hline \multirow[t]{2}{*}{ ICAs } & \multicolumn{2}{|l|}{ Mean } & \multicolumn{2}{|l|}{$\mathrm{SD}$} & \multicolumn{2}{|l|}{ Minimum } & \multicolumn{2}{|c|}{ Maximum } \\
\hline & intraoral & model & intraoral & model & intraoral & model & intraoral & model \\
\hline $\mathrm{CI}+\mathrm{CI}$ & 4.49 & 5.00 & 0.82 & 0.83 & 2.90 & 3.31 & 6.49 & 6.91 \\
\hline CI + LI (R) & 2.81 & 3.11 & 0.62 & 0.60 & 1.79 & 2.11 & 4.12 & 4.41 \\
\hline $\mathrm{LI}+\mathrm{C}(\mathrm{R})$ & 2.27 & 2.53 & 0.83 & 0.80 & 1.41 & 1.64 & 5.83 & 6.04 \\
\hline $\mathrm{C}+\mathrm{FP}(\mathrm{R})$ & 1.64 & 1.99 & 0.65 & 0.60 & 0.63 & 0.98 & 2.52 & 2.88 \\
\hline $\mathrm{CI}+\mathrm{LI}(\mathrm{L})$ & 2.84 & 3.19 & 0.85 & 0.80 & 1.65 & 1.99 & 5.82 & 6.19 \\
\hline $\mathrm{LI}+\mathrm{C}(\mathrm{L})$ & 2.25 & 2.55 & 0.47 & 0.45 & 1.43 & 1.74 & 3.05 & 3.34 \\
\hline $\mathrm{C}+\mathrm{FP}(\mathrm{L})$ & 1.66 & 1.97 & 0.59 & 0.57 & 0.71 & 1.03 & 2.41 & 2.73 \\
\hline
\end{tabular}

$\mathrm{SD}=$ Standard deviation; $\mathrm{CI}=$ central incisor; $\mathrm{LI}=$ lateral incisor; $\mathrm{C}=$ canine; $\mathrm{FP}=$ first premolar; $\mathrm{R}=$ right; $\mathrm{L}=$ left.

contact area). The ICAs measured were: central incisor to central incisor, central incisor to lateral incisor, lateral incisor to canine, and canine to first premolar on both sides of the jaw. Each contact point was measured three times, and the average measurement was recorded.

Upper irreversible hydrocolloid (mint flavor, Alginate Hydrogum, Zhermack) impressions were taken for each participant. Impressions were disinfected and then immediately poured in yellow stone (dental stone type III, Elite Model Thixotropic, Zhermack) with a vacuum mixer (Easy Mix, Bego, Germany) according to the manufacturer's instructions. Untidy, defected and/or badly poured stone casts were excluded, and impressions were retaken. A certified dental technician (Ahmad K. Deep) poured the impressions and trimmed the resulting models. The same interproximal areas were also measured on upper stone models for each patient using the method described by Stappert et al. [7]. The proximal contact areas were measured on the stone models from the apical point of the contact area, corresponding to the peak of the interdental papilla, to the incisal point of the contact area, equivalent to the initiation of the incisal embrasure.

The interproximal contact measurements were performed by one of the investigators (M.G.S.). Intraexaminer reliability was verified by kappa statistics following the remeasurement of the proximal contacts in 3 participants by the same investigator (M.G.S.) after 1 week. Interexaminer reliability was also assessed following remeasuring contact values of the 3 participants by another investigator (M.K.A.) after 1 week.

\section{Statistical Analysis}

The data were analyzed using the Statistical Package for Social Sciences software (SPSS, version 19.0, Chicago, Ill., USA). Simple frequency tables were processed and analyzed by means of ANOVA and paired samples tests to identify any significant differences between the different methods used to measure the contact areas and to identify the differences in the dimensions of contact areas. Pearson's correlation test was used to identify the relationship between contact point dimensions and age and gender. Statistical significance was based on probability values $<0.05$.
Table 2. ANOVA statistical analysis of the differences between the intraoral and model measurements of ICAs of measured teeth

\begin{tabular}{lrrll}
\hline Contacts & $\begin{array}{l}\text { Sum of } \\
\text { squares }\end{array}$ & d.f. & $\begin{array}{l}\text { Mean } \\
\text { square }\end{array}$ & $\begin{array}{l}\text { Significance } \\
(2 \text {-tailed) }\end{array}$ \\
\hline CIs & 102.293 & 149 & 5.683 & 0.000 \\
CI-LI (R) & 53.448 & 149 & 2.813 & 0.000 \\
LI-C (R) & 94.573 & 149 & 6.305 & 0.000 \\
C-FP (R) & 51.973 & 149 & 3.998 & 0.000 \\
CI-LI (L) & 91.848 & 149 & 5.403 & 0.000 \\
LI-C (L) & 29.735 & 149 & 2.287 & 0.000 \\
C-FP (L) & 48.560 & 149 & 4.047 & 0.000 \\
\hline
\end{tabular}

d.f. = Degrees of freedom; $\mathrm{CI}=$ central incisor; $\mathrm{LI}=$ lateral incisor; $\mathrm{C}=$ canine; $\mathrm{FP}=$ first premolar; $\mathrm{L}=$ left; $\mathrm{R}=$ right.

\section{Results}

The mean age of the participants was $32.4 \pm 7.9$ years. The intra- and inter-kappa values were $0.93 \pm 0.01$ and $0.89 \pm 0.03$, respectively, showing high intra- and interexaminer reliability. The largest contact point was the one present between the central incisors, ranging from 2.9 to $6.49 \mathrm{~mm}$ when measured intraorally and from 3.31 to $6.91 \mathrm{~mm}$ when measured on the models. On the other hand, the contact point between the canine and first premolar was the smallest on both sides of the arch and ranged from 0.63 to $2.52 \mathrm{~mm}$ when measured intraorally and from 0.98 to $2.88 \mathrm{~mm}$ when measured on the models. The means, standard deviations and range of the interproximal contact point distances among the measured teeth both intraorally and on the models are given in table 1 . 
Table 3. Paired samples t test statistical analysis of the differences between the intraoral measurements of ICAs of measured teeth

\begin{tabular}{|c|c|c|c|c|c|c|}
\hline \multirow[t]{2}{*}{ Contacts } & \multirow[t]{2}{*}{$\begin{array}{l}\text { Standard error } \\
\text { of the mean }\end{array}$} & \multicolumn{2}{|c|}{$\begin{array}{l}95 \% \text { confidence interval } \\
\text { of the difference }\end{array}$} & \multirow[t]{2}{*}{$\mathrm{t}$ test } & \multirow[t]{2}{*}{ d.f. } & \multirow[t]{2}{*}{$\begin{array}{l}\text { Significance } \\
\text { (2-tailed) }\end{array}$} \\
\hline & & lower & upper & & & \\
\hline Pair 1: CIs + CI-LI (R) & 0.08438 & 1.62992 & 1.96341 & 21.291 & 149 & 0.000 \\
\hline Pair 2: CI-LI (R) + LI-C (R) & 0.09143 & 0.32933 & 0.69067 & 5.578 & 149 & 0.000 \\
\hline Pair 3: LI-C (R) + C-FP (R) & 0.08365 & 0.50804 & 0.83863 & 8.049 & 149 & 0.000 \\
\hline Pair 4: CIs + LI-CI (L) & 0.07698 & 1.63789 & 1.94211 & 23.254 & 149 & 0.000 \\
\hline Pair 5: CI-LI + LI-C (L) & 0.07514 & 0.44485 & 0.74181 & 7.896 & 149 & 0.000 \\
\hline Pair 6: LI-C + C-FP (L) & 0.05272 & 0.46583 & 0.67417 & 10.812 & 149 & 0.000 \\
\hline
\end{tabular}

d.f. = Degrees of freedom; $\mathrm{CI}=$ central incisor; $\mathrm{LI}=$ lateral incisor; $\mathrm{C}=$ canine; $\mathrm{FP}=$ first premolar; $\mathrm{L}=$ left; $\mathrm{R}=$ right.

Table 4. Paired samples $t$ test statistical analysis of the differences between the model measurements of ICAs of measured teeth

\begin{tabular}{|c|c|c|c|c|c|c|}
\hline \multirow[t]{2}{*}{ Contacts } & \multirow[t]{2}{*}{$\begin{array}{l}\text { Standard error } \\
\text { of the mean }\end{array}$} & \multicolumn{2}{|c|}{$\begin{array}{l}95 \% \text { confidence interval } \\
\text { of the difference }\end{array}$} & \multirow[t]{2}{*}{ t test } & \multirow[t]{2}{*}{ d.f. } & \multirow[t]{2}{*}{$\begin{array}{l}\text { Significance } \\
\text { (2-tailed) }\end{array}$} \\
\hline & & lower & upper & & & \\
\hline Pair 1: CIs + CI-LI (R) & 0.08438 & 1.72992 & 2.06341 & 22.477 & 149 & 0.000 \\
\hline Pair 2: CI-LI (R) + LI-C (R) & 0.09143 & 0.39933 & 0.76067 & 6.344 & 149 & 0.000 \\
\hline Pair 3: LI-C (R) + C-FP (R) & 0.08365 & 0.36804 & 0.69863 & 6.376 & 149 & 0.000 \\
\hline Pair 4: CIs + LI-CI (L) & 0.07698 & 1.65789 & 1.96211 & 23.513 & 149 & 0.000 \\
\hline Pair 5: CI-LI + LI-C (L) & 0.07514 & 0.49485 & 0.79181 & 8.562 & 149 & 0.000 \\
\hline Pair 6: LI-C + C-FP (L) & 0.05272 & 0.47583 & 0.68417 & 11.002 & 149 & 0.000 \\
\hline
\end{tabular}

d.f. = Degrees of freedom; $\mathrm{CI}=$ central incisor; $\mathrm{LI}=$ lateral incisor; $\mathrm{C}=$ canine; $\mathrm{FP}=$ first premolar; $\mathrm{L}=$ left; $\mathrm{R}=$ right.

Pearson's correlation test showed no significant relationship between the dimension of the measured contact points and age and gender $(p>0.05)$, regardless of being measured intraorally or on models. Statistical analysis using the ANOVA test showed that the intraoral measurement of contact points was more accurate than that on models, and the differences were statistically significant $(\mathrm{p}<0.001)$ (table 2).

The dimensions of the contact points declined as we moved from anterior to back areas (fig. 2). Both measurement techniques showed that the dimensions of interproximal contacts on both sides of each tooth were significantly different $(\mathrm{p}<0.001)$ and that the dimension of the mesial contact point was larger than that of the distal contact point of each tooth (tables 3, 4). The declination of the dimensions of the contact points as we moved from the anterior to the back area is shown in figure 2. The dimensions of the contact point decreased as we moved from the contact between central incisors to that between the canine and first premolar.

\section{Discussion}

In this study, the directly measured apicoincisal heights of the ICA inside patients' mouths using a digital caliper were more accurate than those obtained on stone models. A probable explanation could be the problems associated with taking impressions by forcing the papilla apically and the distortions of the impression and expansion of stone models during the construction of the models. 


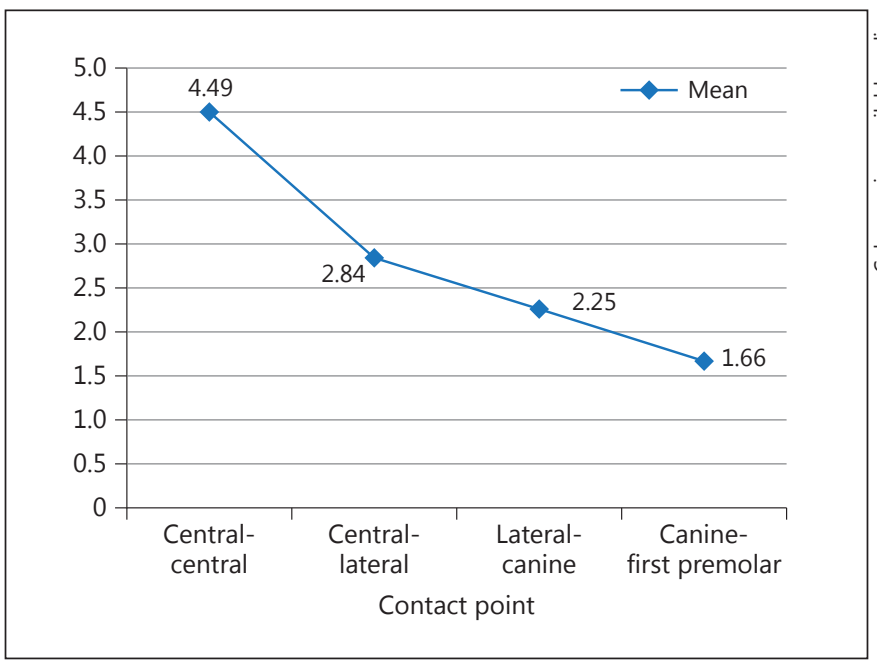

Fig. 2. The trend of declination of the dimensions of the contact points from the anterior area backwards (in millimeters).

Also in this study, the interproximal contacts of upper teeth in the esthetic zone (from first premolar to first premolar) were measured as in previous studies $[7,14]$, in which the interproximal contacts were measured and stopped at first premolars using other methods of measurement. It was decided that the measured upper maxillary area up to the first premolar is more easily accessible, and this would avoid any potential effects of measurement errors due to poor visibility, as this technique was only just introduced and validated. Also, it would facilitate a comparison of the results of this study with those of previous studies. In our study, the mean interproximal contact heights ranged from $4.49 \mathrm{~mm}$ (for central incisors) to $1.66 \mathrm{~mm}$ (for contacts between canines and first premolars). Meanwhile, other studies [7, 14, 15] reported mean interproximal contact heights of 4.2-4.6 $\mathrm{mm}$ (for central incisors) and 1.5-1.6 mm (for contacts between canines and first premolars). The differences between the current study and previous ones could be attributed to the different methods used to measure contact points as discussed above. Also, the differences could be due to the use of a larger sample size (150 participants) in the current study in comparison to only 20-30 participants in previous studies $[7,14,15]$ and the use of different participants with different genetic backgrounds in comparison to those used by other studies $[7,15]$.

The value of ICA during the restoration of anterior teeth was investigated in previous studies $[3,7,9-12]$ on smile esthetics. However, the height of the ICA was not directly measured intraorally in any of these studies. Stappert et al. [7] evaluated proximal contacts on master models in an apicoincisal direction by measuring the contact area from the top of the interdental papilla to the start of the incisal embrasure. Other investigators $[3,5]$ used the technique of sounding the soft tissues to evaluate the distance between the facial side of the apical portion of the contact area and the crest of the alveolar bone and periapical radiographs to assess contact area dimensions [3].

However, although the interdental papilla that corresponds to the apical point of the contact area measured using the above methods might not provide the most accurate measurement of the contact area just as our stone models did not, probably due to forcing the papilla apically during the process of taking the impression, expansion of and problems associated with using radiographs to make such measurements include distortion, overlap of adjacent structures and difficulty in getting perfect parallelism during radiography.

In our study, the measured height of ICAs was different for different teeth regardless of intraoral measurement or measurements on models, because the height of the contact area decreased from anterior to posterior contacts. The contact area between the central incisors was the largest and the one between the canine and premolar tooth was the smallest. A probable explanation could be the anatomical tooth form and the inclinations at which adjacent teeth meet each other. The trend of a reduction in dimensions of the contact point from anterior to posterior contacts was similar to the findings of previous studies $[7,14,15]$.

A further explanation for this finding could be that teeth are arranged with tectonic spacing, an arrangement that is both functional and esthetic [8]. For example, soon after the alignment of teeth in both arches, a positive contact relation occurs mesially and distally between one tooth and adjacent teeth. This contact relation serves to keep food from packing between teeth, and it helps to stabilize the dental arch by the combined anchorage of all teeth. Equally, this proper contact gives good esthetics by avoiding the formation of black triangles. Hence, extra efforts and attention should be given to the accurate evaluation of the height of the proximal contact area.

Future research is needed to use this technique for other parts of the dental arch. In addition, it would be very helpful if future research considered a calculation of the percentage ratio of interproximal contact dimension related to the length of the clinical crown [15]. 


\section{Conclusions}

The apicogingival dimension of the contact point decreased from anterior to posterior teeth. The contact area between the central incisors was the largest and the one between canines and premolars was the smallest. The clinical evaluation of contact point dimensions using a digital caliper is a viable, quick and accurate method.

\section{Acknowledgement}

This study was supported by Aljouf University, Sakaka, Saudi Arabia (grant No. 33/106).

We would like to thank Ahmad K. Deep for his technical assistance.

\section{References}

1 Foulger TE, Tredwin CJ, Gill DS, et al: The influence of varying maxillary incisal edge Embrasure space and interproximal contact area dimensions on perceived smile aesthetics. Br Dent J 2010;209:E4.

2 Nelson SJ: Weelar's Dental Anatomy, Physiology, and Occlusion. Philadelphia, Saunders, 1984, pp 20-25.

3 Martegani P, Silvestri M, Mascarello F, et al: Morphometric study of the interproximal unit in the esthetic region to correlate anatomic variable affecting the aspect of soft tissue embrasure space. J Periodontol 2007;78: 2260-2265.

4 Somanathan RV, Simunek A, Bukac J, et al: Soft tissue esthetics in implant dentistry. Acta Medica (Hradec Kralove) 2007;50:183-186.
5 Tarnow DP, Magner AW, Fletcher P: The effect of the distance from the contact point to the crest of bone on the presence or absence of the interproximal dental papilla. J Periodontol 1992;63:995-996.

6 Suilkowski A: Essentials in aesthetics; in Tarnow DP, Chu SJ, Kim J (eds): Aesthetic Restorative Dentistry: Principles and Practice. Mahwah, Montage Media, 2008, p 616.

7 Stappert CFJ, Tarnow DP, Chu SJ: Proximal contact areas of the maxillary anterior dentition. Int J Periodontics Restorative Dent 2010; 30:471-477.

8 Ahmad I: Anterior dental aesthetics: historical perspective. Br Dent J 2005;198:737-742.

9 Levin El: Dental esthetics and the golden proportion. J Prosthet Dent 1978;40:244-252.

10 Ward DH: Proportional smile design using the recurring esthetic (RED) proportion. Dent Clin North Am 2001;45:143-154.

11 Brunzel S, Kern M, Freitag S, et al: Aesthetics effect of minor changes in incisor angulation: an internet evaluation. J Oral Rehabil 2006;33: 430-435.
12 Spear FM: Interdisciplinary aesthetic management of anterior gingival embrasures. Adv Esthet Interdisciplinary Dent 2006;2:20-28

13 Cho HS, Jang HS, Kim DK, et al: The effect of interproximal distance between roots on the existence of interdental papillae according to the distance from the contact point to the alveolar crest. J Periodontol 2006;77:16511657.

14 Sghaireen MG, Al-Zarea BK, Al-Shorman $\mathrm{HM}$, et al: Clinical measurement of the height of the interproximal contact area in maxillary anterior teeth. Int J Health Sci 2013;7:325330.

15 Stappert CF, Tarnow DP, Tan JH, et al: Proximal contact areas of the maxillary anterior dentition. Int J Periodontics Restorative Dent 2010;30:471-477. 